\title{
Dynamic Properties of Magnesium Alloys
}

\author{
ALOK SINGH ${ }^{1,3}$ and JAMES E. SAAL ${ }^{2,4}$ \\ 1.-National Institute for Materials Science, 1-2-1 Sengen, Tsukuba, Ibaraki 305-0047, Japan. \\ 2.-Department of Materials Science and Engineering, Northwestern University, Evanston, \\ IL 60298, USA. 3.—e-mail: alok.singh@nims.go.jp. 4.—e-mail: j-saal@northwestern.edu
}

With the rapidly expanding use of automobiles globally, the application of lighter structural materials in the form of magnesium alloys has become an urgent necessity to improve fuel efficiency and reduce the environmental impact. Within automobiles, magnesium alloys are used for components such as steering wheel frames and wheel rims, which are subjected to not only quasi-static but also dynamic strains. Indeed, catastrophic failure of a component by dynamic strain effects is a critical consideration, such as that of a wheel rim by braking at a high speed of $320 \mathrm{~km} / \mathrm{h} .{ }^{1}$ A recent consideration of magnesium for crash rail applications was rapidly brought to an end by the poor performance of initial crash test results. ${ }^{2}$ Dynamic strain rate testing is also important because of the emergence of magnesium alloys for armor with good ballistic properties. $^{3}$

Just as with quasi-static strain, the mechanical behavior at dynamic strain rates depends on the microstructure. Deformation at dynamic strain rates produces more uniform distribution of dislocations and hinders the formation of discrete dislocation cells. ${ }^{4}$ Suppression of thermally activated dislocation processes occurs in this regime, which can lead to stresses high enough to activate deformation twins even in face-centered cubic (fcc) alloys with the high-stacking-fault energy. Among the fcc, body-centered cubic (bcc), and hexagonal closepacked (hcp) metals and alloys, high-purity fcc metals exhibit yielding that is nearly independent of the strain rate, while the strain hardening after yielding is strongly dependent on strain rate, which is due to the suppression of dynamic recovery process. In the case of bcc metals and alloys, yielding is strongly dependent on strain rate, while strain hardening is independent of the strain rate. For hcp metals, both the yielding and the strain hardening are dependent on strain rate. ${ }^{4}$

In hep metals and alloys, twins play a very important role in deformation, especially for magnesium alloys in which nonbasal slips are not easily activated. The texture and $c / a$ ratio greatly influ- ence the deformation behavior of hep metals. The effects of the polarity of twinning are similar to that at quasi-static tests. During in-plane testing of rolled plates with strong basal texture, in which the basal planes are parallel to the loading direction, it is observed that the twinning propensity increases with increasing strain rate. ${ }^{4,5}$ Through-thickness dynamic testing, in which the loading direction is perpendicular to the basal planes, reveals that the main deformation twinning mode, $\{10 \overline{1} 2\}$ extension twinning, may not be activated. As a result, the work-hardening response in in-plane loading is more sensitive to strain rate than through-thickness loading. ${ }^{5}$

In this issue, we have four contributions on the dynamic behavior of magnesium alloys. The first is titled, "Dynamic Behavior of a Rare-Earth-Containing Mg Alloy WE43B-T5 Plate with Comparison to Conventional Alloy AM30-F" by S.R. Agnew, W. Wittington, A. Oppedal, H. El Kadiri, M. Shaeffer, K.T. Ramesh, J.J. Bhattacharyya, R. DeLorme, and B. Davis, which compares the dynamic behavior of two wrought alloys, a rolled WE43B alloy in peakaged condition, and an extruded AM30 alloy. The WE43B plate exhibited a relative isotropy of yield strength at quasi-static and dynamic strain rates, although it did show tension-compression strength asymmetry and anisotropy in strain hardening, which is consistent with the texture. The extruded AM30 alloy showed stronger anisotropy in strainhardening behavior related to the stronger texture in this material. At larger strain levels, the rate sensitivities along different directions converge in both the alloys. The authors also report that the yield strength is insensitive to strain rates along loading directions in which the rate-controlling process is $\{10 \overline{1} 2\}$ type twinning, which is known to be relatively rate insensitive.

The second contribution titled, "Dynamic Behavior of Some Magnesium Alloys" by E.S. Prasad, B. Li, N. Dixit, M. Shaefer, S.N. Mathaudhu, and K.T. Ramesh investigates the two important alloys, $\mathrm{AZ31B}$ and ZK60, at fine grain and ultrafine grain 
(UFG) sizes with various textures produced by equal-channel angular extrusion (ECAE). The authors also provide an extensive review of the literature and comparison of their results to those previously reported, especially with those with a different texture from extrusion. UFG ZK60 alloys show very little sensitivity to strain rate at lower strains but larger strain hardening rates at higher strains for higher strain rates. Variations in grain size and texture in AZ31B alloy lead to significant differences in yield stress and strain hardening at high strain rates. This alloy shows extensive shear, including apparent shear localization even at very low strain at high-strain-rate deformation. Deformation twins were not easily observed by transmission electron microscopy (TEM) after deformation; Nagao et al. also discuss this in another contribution in this issue.

In the contribution titled, "Deformation Behavior of Binary Mg-Y Alloy under Dynamic Compression Loading," M. Nagao, T. Terada, H. Somekawa, A. Singh and T. Mukai report on investigation on an extruded Mg-0.6 at.\% Y alloy at a high strain rate and compare with pure magnesium. Very little anisotropy of deformation is observed. A detailed characterization by electron backscattered diffraction (EBSD) and TEM finds (I) that twins formed initially do not lead to cracking but instead to the formation of subgrains and (II) that lattice rotations about the $c$-axis occur during dynamic compression, resulting in large strains of about 0.4.

Another contribution titled, "Heat Treatment of AZ91D Mg-Al-Zn Alloy: Microstructural Evolution and Dynamic Response," by D.D. Luong, V.C. Shunmugasamy, J. Cox, N. Gupta, and P.K. Rohatgi, deals with another dimension of highstrain-rate deformation-that of the effect of distribution of intermetallic phase particles in a highpressure die cast AZ91D alloy. Compression testing under a high strain rate resulted in a very significant increase in strength with strain rate for the aged (T6) specimens, attributed to increased energy absorption by $\beta$-phase under high-strain-rate compression. At high strain rates, more deformation was observed in the intermetallic phase than in the matrix.
This issue also contains a contribution titled, "A Study on the Hot Deformation Behavior of Cast Mg-4Sn-2Ca (TX42) Alloy," by K. Suresh, K.P. Rao, Y.V.R.K. Prasad, N. Hort, and K.U. Kainer, which studies hot-deformation behavior of a cast TX42 alloy across a wide range of temperatures and strain rates. At high temperatures in the range of 300$500^{\circ} \mathrm{C}$, strain-rate-dependent yielding and strain hardening are observed. Two domains for hot working on the temperature-strain rate processing map are established. Even though the deformation rates examined in this study are not in the $1000 \mathrm{1} / \mathrm{s}$ range examined by the previous articles, the results are very informative about the upper strain rate limit that may be used for successful forming of this alloy. At the lower end of deformation temperature $\left(300^{\circ} \mathrm{C}\right)$, instability sets in over strain rates of $10^{-2} /$ $\mathrm{s}$, and this regime progressively shifts to strain rates of over $10^{1} / \mathrm{s}$ with increasing deformation temperature. The yield stress becomes more sensitive to strain rate at higher temperatures.

By looking from various angles, these contributions bring significant new understanding to the dynamic behavior of magnesium alloys, which should help the research community conceive of better alloys and microstructures for such components as lightweight crash members and armor.

\section{ACKNOWLEDGMENTS}

Authors would like to thank Prof. Sean Agnew for valuable suggestions.

\section{REFERENCES}

1. Formula One Sebastien Buemi Crash China $2010(\mathrm{Mg}$ rim-racecar failure) (2010), http://www.youtube.com/ watch? $\mathrm{v}=\mathrm{xwo}$ CLiyzdgU.

2. United States Council for Automotive Research, Magnesium Front End Research and Development (2010), http://www1. eere.energy.gov/vehiclesandfuels/pdfs/merit_review_2010/ lightweight_materials/lm008_luo_2010_o.pdf.

3. J. Hamilton, S.T. Brennan, Y. Sohn, B. Davis, R. DeLorme, and K. Cho, Magnesium Technology, ed. S.N. Mathaudhu, W.H. Sillekens, N.R. Neelameggham, and N. Hort (Warrendale, PA: TMS, 2012), p. 433.

4. G.T. Gray III, Ann. Rev. Mater. Res. 42, 285 (2012).

5. V. Livescu, C.M. Cady, E.K. Carreta, B.L. Henrie, and G.T. Gray III, Magnesium Technology, ed. A.A. Luo, N.R. Neelameggham, and R.S. Beals (Warrendale, PA: TMS, 2006), p. 153. 